\title{
Comparison of Pegfilgrastim and Filgrastim for the Primary Prophylactic Effect for Preventing Febrile Neutropenia in Patients Undergoing Rituximab with Dose-adjusted EPOCH Chemotherapy
}

\author{
Tatsuo Kataoka, ${ }^{*}$ Hiroshi Sakurashita, Takanori Taogoshi, Ryo Nishigakiuchi, Tetsuya Murase, \\ Satoru Izumitani, Yasuyuki Saeki, and Hiroaki Matsuo
}

Department of Pharmacy, Hiroshima University Hospital; 1-2-3 Kasumi, Minami-ku, Hiroshima 734-8551, Japan.

(Received May 14, 2018; Accepted December 12, 2018)

\begin{abstract}
The combination of dose-adjusted etoposide, prednisone, vincristine, cyclophosphamide and doxorubicin with rituximab (DA-EPOCH-R) is used for non-Hodgkin lymphoma patients. Febrile neutropenia (FN) is a common complication of treatment with myelo-suppressive chemotherapy, so preventing FN is important for maintaining chemotherapy dosage. Recently, pegfilgrastim has been used as the primary prophylaxis of FN in Japan, but there have been few cases reported using pegfilgrastim for the primary prophylaxis in DA-EPOCH-R. In this study, we retrospectively compared the efficacy of pegfilgrastim with that of filgrastim in patients receiving DA-EPOCH-R in Hiroshima University Hospital. Efficacy assessment was based on incidence of FN and serious neutropenia (neutrophil count $<500 / \mu \mathrm{L}$ ), hospitalization days and chemotherapy dosage level. Ten patients met the inclusion criteria: pegfilgrastim $(n=5,30 \mathrm{cy}-$ cles) or filgrastim ( $n=5,16$ cycles). No difference in efficacy existed between pegfilgrastim and filgrastim in the first cycle; however, 2 of 5 patients in filgrastim group reduced dose level in the total cycles of chemotherapy, no patients in pegfilgrastim group reduced. In conclusion, pegfilgrastim seemed better than filgrastim for the primary prophylaxis in DAEPOCH-R.
\end{abstract}

Key words — pegfilgrastim; filgrastim; primary prophylaxis; dose-adjusted etoposide, prednisolone, vincristine, cyclophosphamide and doxorubicin with rituximab chemotherapy

\section{INTRODUCTION}

Febrile neutropenia (FN) was defined as an axillary temperature above $37.5^{\circ} \mathrm{C}$ or oral temperature above $38.0^{\circ} \mathrm{C}$ and an absolute neutrophil count (ANC) $<500 / \mu \mathrm{L}$ or $\mathrm{ANC}<1000 / \mu \mathrm{L}$ and expected to fall below $500 / \mu \mathrm{L}$ within $48 \mathrm{~h}$, according to the definition of FN in the Clinical Practice guideline for FN in Japan. ${ }^{1)}$ When FN occurs, we decrease chemotherapy dose and/or delay chemotherapy treatment schedule; these approaches lead to an effect on relative dose intensity (RDI). This is the reason prevention of $\mathrm{FN}$ is a very important matter. Pettengell et al. reported about patients with non-Hodgkin lymphoma (NHL) who received prednisone, vincristine, cyclophosphamide and doxorubicin (CHOP) chemotherapy. The group receiving reduced chemotherapy (RDI $\leq 90 \%)$ had reduce overall survival compared with the RDI $>$ 90\% group. ${ }^{2)}$ From this report, preventing FN or neutropenia seems to have a potential impact for chemotherapy outcome. Recently, dose-adjusted etoposide, prednisone, vincristine, cyclophosphamide and doxorubicin with rituximab (DA-EPOCH-R)

\footnotetext{
*e-mail: ta-kataoka0208@ hiroshima-u.ac.jp
}

regimen has been used for NHL patients. In the DAEPOCH-R regimen, granulocyte colony-stimulating factor (G-CSF) is recommended to use for individual patient dose adjustment. ${ }^{3)}$ In Hiroshima University Hospital, patients receiving DA-EPOCH-R were often given G-CSF for individual patient dose adjustment and the primary prophylaxis of FN. Recently, pegfilgrastim was approved in Japan for the primary prophylaxis of FN. Pegfilgrastim seems to better effect than filgrastim in reducing $\mathrm{FN}$ in some reports, ${ }^{4-6)}$ however in these studies pegfilgrastim mainly used higher dose than Japan (6 mg vs. 3.6 $\mathrm{mg}$ ). In Japanese study showed non-inferiority of a single subcutaneous dose of pegfilgrastim compared with daily subcutaneous doses of filgrastim, ${ }^{7)}$ however these effect was not clear in clinical practice. Pegfilgrastim was used instead of daily G-CSF in the DA-EPOCH-R regimen; however, few cases have been reported about using pegfilgrastim for the primary prophylaxis of FN and dose adjustment in DAEPOCH-R and its efficacy has been poorly understood. In this study, we retrospectively compared the efficacy of pegfilgrastim with filgrastim used for this purpose in patients receiving DA-EPOCH-R. 


\section{PATIENTS AND METHODS}

Study Design and Patient Selection This study was approved by the Hiroshima University Institutional Ethical Committee (approval No. E-401).

Consecutive patients with aggressive NHL who received the DA-EPOCH-R regimen were screened from April 2013 to February 2017. The patients enrolled in this study fulfilled the following criteria: (1) received filgrastim or pegfilgrastim for the primary prophylaxis in the first cycle; (2) received DAEPOCH-R regimen Level 1 dose in the first cycle; (3) no fixed dosage with renal or hepatic function. We excluded patients who received filgrastim or pegfilgrastim with $\mathrm{ANC}<1000 / \mu \mathrm{L}$ in the first cycle. Patients were divided into two group according to the drug received, daily subcutaneous injection of Gran ${ }^{\circledR}$ or biosimilars of filgrastim (filgrastim) (FG group) or single subcutaneous injection of G-Lasta ${ }^{\circledR}$ (pegfilgrastim) (PEG group).

Data Collection Data were collected and managed using Data Warehouse database system. Age, sex, performance status, chemotherapy history, bone marrow infiltration, date of chemotherapy initiation and completion, the number of chemotherapy cycles, date of filgrastim initiation and completion, complete blood counts (CBCs), date of FN onset and hospital duration from start of chemotherapy were extracted from medical records. Hospital duration was decided by the physician considering patient condition and myelosuppression; at first cycle, patient could leave hospital after recovery of myelosuppression with physician's decision.

We defined the CBCs measured within $7 \mathrm{~d}$ before administration of the DA-EPOCH-R regimen as initial blood test value.

Chemotherapy and Dose Adjustment DA$\mathrm{EPOCH}$ regimen was administered as previously described $^{3)}$ with slight modification. Prednisone was changed to prednisolone and vincristine capped at 2 mg (Table 1 shows Level 1 dose DA-EPOCH-R regimen). Rituximab was administered at a fixed dose of $375 \mathrm{mg} / \mathrm{m}^{2}$ per day of body surface area and administration date was decided by the physician in charge. Cycles were administered at intervals of at least $21 \mathrm{~d}$ and the pharmacodynamics dose adjustment was based on CBCs at the nadir of each cycle. Filgrastim $75 \mu \mathrm{g}$ per day was administered at least $24 \mathrm{~h}$ after chemotherapy until post nadir or pegfilgrastim $3.6 \mathrm{mg} /$
Table 1. Dose-adjusted Etoposide, Prednisolone, Vincristine, Cyclophosphamide, Doxorubicin, Rituximab Regimen in Hiroshima University Hospital (Level 1 dose)

\begin{tabular}{lccc}
\hline \hline \multicolumn{1}{c}{ Drug } & Dose & Route & Treatment days \\
\hline Etoposide & $50 \mathrm{mg} / \mathrm{m}^{2} / \mathrm{d}$ & civ & $1,2,3,4$ \\
Doxorubicin & $10 \mathrm{mg} / \mathrm{m}^{2} / \mathrm{d}$ & civ & $1,2,3,4$ \\
Vincristine & $0.4 \mathrm{mg} / \mathrm{m}^{2} / \mathrm{d}$ & civ & $1,2,3,4$ \\
Cyclophosphamide & $750 \mathrm{mg} / \mathrm{m}^{2} / \mathrm{d}$ & div & 5 \\
Prednisolone & $60 \mathrm{mg} / \mathrm{m}^{2} / \mathrm{d}$ & div or po & $1,2,3,4,5$ \\
Rituximab & $375 \mathrm{mg} / \mathrm{m}^{2} / \mathrm{d}$ & div & \\
G-CSF & & sc & $6 \sim$ \\
& & & Next cycle Day 21 \\
\end{tabular}

G-CSF: granulocyte colony-stimulating factor. civ: continuous intravenous drip infusion. div: intravenous drip infusion. po: per os. sc: subcutaneously.

cycle was administered similarly.

Evaluation of Efficacy and Adverse Event In the first cycle, we checked the white blood cell (WBC) count, ANC, incidence of FN, duration of filgrastim use, hospital duration from start of chemotherapy, and dose level at second cycle.

The duration of filgrastim was defined as days filgrastim used for preventing FN, so days filgrastim used after incidence of FN were not included in the duration.

In total cycles, we checked incidence of leukopenia (Grade 4), neutropenia (Grade 4) and FN, duration of filgrastim use, hospital duration from start chemotherapy; average of hospital duration in each cycle, and dose level change. We checked bone pain for adverse event. Each adverse event was graded according to the National Cancer Institute Common Toxicity Criteria (version 4.0).

Statistical Analysis Analysis of the patient's background and other normal distributions was performed using the Student's $t$-test; for non-normal distributions we used the Mann-Whitney $U$ test. Analysis of incidence of FN, leukopenia or neutropenia and dose level of chemotherapy was performed using the Fisher's exact test. $p<0.05$ was considered statistically significant.

\section{RESULTS}

Patient Characteristics Twenty patients with NHL received the DA-EPOCH-R regimen from April 2013 to February 2017 and 10 of them were excluded from analysis. Five of them were given G-CSF after ANC fell to less than $1000 / \mu \mathrm{L}, 3$ received fixed chemotherapy dosage with renal function, and the 
Table 2. Summary of Patient Characteristics

\begin{tabular}{lccc}
\hline \multicolumn{1}{c}{ Patient } & FG $(n=5)$ & PEG $(n=5)$ & $p$-value \\
\hline & $\mathrm{A}-\mathrm{E}$ & $\mathrm{F}-\mathrm{J}$ & \\
Sex (male/female) & $4 / 1$ & $4 / 1$ & 1.0 \\
Age (year) & $59.4(35-78)$ & $47.6(33-70)$ & 0.29 \\
Body surface area $\left(\mathrm{m}^{2}\right)$ & 1.70 & 1.69 & 0.89 \\
$\begin{array}{l}\text { Bone marrow infiltration } \\
\text { (Yes/No) }\end{array}$ & $1 / 4$ & $0 / 5$ & 1.0 \\
$\begin{array}{l}\text { Previous chemotherapy } \\
\text { treatment (Yes/No) }\end{array}$ & $2 / 3$ & $1 / 4$ & 1.0 \\
$\begin{array}{l}\text { Performance status } \\
(0 / 1 / \geq 2)\end{array}$ & $4 / 1 / 0$ & $3 / 2 / 0$ & \\
\hline
\end{tabular}

Age and body surface area are shown mean (min-max). Performance status was corrected by physician records. FG: filgrastim group, PEG: pegfilgrastim group.

other 2 received a higher dose of filgrastim than used in this study $(300 \mu \mathrm{g} /$ body $)$. Clinical characteristics of 10 patients are shown in Table 2. Five patients were in the FG group (patient $\mathrm{A}$ to $\mathrm{E}$ ) and others were in the PEG group (patient $\mathrm{F}$ to $\mathrm{J}$ ). Patient factors associated with a high FN risk according to ASCO and NCCN guidelines - patient age $(>65)$, poor performance status $(>2)$ and chemotherapy history-were not significantly different in the two groups (Table 2 and Supplementary Table S1).

Evaluation of Efficacy and Adverse Event In 3 of 5 patients in the FG group, the G-CSF received was changed to pegfilgrastim from filgrastim at a certain cycle, and these cycles were excluded from analysis. In the PEG group, no patients received filgrastim.

A summary of data at the first cycle is shown in Table 3. The number of incidence of FN was the same between the two groups; the FG group tended to have lower WBC and ANC count in the nadir than the PEG group. Hospital duration from start of chemotherapy was not significantly different in the two groups $(p=0.55)$. Patient $\mathrm{G}$ in the PEG group received 2 cycles of chemotherapy without being discharged from the hospital; it must have influenced hospital duration analysis (Supplementary Table S2).

Sixteen cycles from 5 patients in the FG group and 30 cycles from 5 patients in the PEG group were analyzed. Data at the total cycles is shown in Table 4. In the FG group, patient $\mathrm{B}$ and $\mathrm{C}$ received a lower dose of chemotherapy, however no patient received a lower dose in the PEG group (Table 4). Patients in the PEG group had lower incidence of leukopenia (Grade 4), neutropenia (Grade 4) and FN than
Table 3. Summary of Results in First Cycle

\begin{tabular}{|c|c|c|c|}
\hline & $\begin{array}{c}\mathrm{FG} \\
(n=5)\end{array}$ & $\begin{array}{l}\text { PEG } \\
(n=5)\end{array}$ & $p$-value \\
\hline Leukopenia (Grade 4), $n(\%)$ & $3(60.0)$ & $0(0.0)$ & 0.17 \\
\hline Neutropenia (Grade 4), $n(\%)$ & $3(60.0)$ & $1(20.0)$ & 0.52 \\
\hline Febrile neutropenia, $n(\%)$ & $1(20.0)$ & $1(20.0)$ & 1.00 \\
\hline Filgrastim use duration (d) & $\begin{array}{c}6.4 \\
(4-10)\end{array}$ & & \\
\hline$<10 \mathrm{~d}$ & 4 & & \\
\hline$\geq 10 \mathrm{~d}$ & 1 & & \\
\hline $\begin{array}{l}\text { Hospital duration from start of } \\
\text { chemotherapy (d) }\end{array}$ & $\begin{array}{c}19.0 \\
(14-23)\end{array}$ & $\begin{array}{c}16.2 \\
(10-33)\end{array}$ & 0.55 \\
\hline Reduced dose level to $<1$ & $1(20.0)$ & $0(0.0)$ & 1.00 \\
\hline
\end{tabular}

patients in the FG group. Moreover, hospital duration from start of chemotherapy in the PEG group was significantly shorter than that in the FG group ( $p$ $<0.01$ ) (Table 4 ). There were no dose adjustment by thrombocytopenia.

In the PEG group, 3 patients experienced bone pain, on the other hand, FG group none. No patient stopped pegfilgrastim by adverse event.

\section{DISCUSSION}

In this retrospective study, pegfilgrastim seemed to have better efficacy than filgrastim for use to prevent FN in patients given the DA-EPOCH-R regimen.

In the DA-EPOCH-R regimen, we can modify the chemotherapy dosage based on patient tolerability affected by clearance of chemotherapy drugs. ${ }^{3)}$ For this reason, DA-EPOCH had a better outcome than CHOP in NHL lymphoma patients. ${ }^{8)}$ We adjusted dose level in each cycle according to the depth of the hematologic nadir, and neurotoxicity. ANC reduction $(<500 / \mu \mathrm{L})$ was one of these dose-limiting factors;3) primary administration of G-CSF for preventing reduction of ANC and RDI is very important in treatment of DA-EPOCH.

The incident rate of $\mathrm{FN}$ in patients who received the DA-EPOCH-R regimen in our study was $10.8 \%$ (five of 46 cycles). This was similar to previous reports. ${ }^{8,9)}$ Though patient characteristics were not different between the two groups, the PEG group tended to have higher WBC and ANC count in the nadir in the first cycle, and reduced incidence of severe neutropenia and FN in total cycles. Previous reports showed that pegfilgrastim prophylaxis reduced hospitalization of 
Table 4. Results Data in Total Cycles

\begin{tabular}{|c|c|c|c|c|c|c|}
\hline Patient & $\begin{array}{l}\text { Number of } \\
\text { inclusion cycles }\end{array}$ & $\begin{array}{l}\text { Neutropenia } \\
\text { (Grade 4) }\end{array}$ & $\begin{array}{c}\text { Febrile } \\
\text { neutropenia }\end{array}$ & $\begin{array}{l}\text { Filgrastim } \\
\text { use duration }\end{array}$ & $\begin{array}{l}\text { Hospital duration from } \\
\text { start chemotherapy }\end{array}$ & Dose level \\
\hline \multicolumn{7}{|l|}{ FG } \\
\hline A & 4 & 3 & 0 & $7.3(6-8)$ & $19.5(15-23)$ & $1,1,1,1$ \\
\hline B & 4 & 3 & 1 & $9.0(8-10)$ & $19.8(18-22)$ & $1,1,-1,-1$ \\
\hline $\mathrm{C}$ & 1 & 1 & 1 & 4 & 20 & 1 \\
\hline $\mathrm{D}$ & 6 & 3 & 2 & $3.7(2-6)$ & $12.6(10-18)$ & $1,2,2,3,2,2$ \\
\hline $\mathrm{E}$ & 1 & 0 & 0 & 4 & 14 & 1 \\
\hline \multicolumn{7}{|l|}{ PEG } \\
\hline $\mathrm{F}$ & 6 & 0 & 0 & - & $8.2(7-10)$ & $1,1,1,1,1,1$ \\
\hline $\mathrm{G}$ & 6 & 1 & 1 & - & $12.2(7-33)$ & $1,1,2,3,3,3$ \\
\hline $\mathrm{H}$ & 6 & 2 & 0 & - & $7.3(6-14)$ & $1,2,3,4,5,5$ \\
\hline I & 6 & 0 & 0 & - & $9.3(7-12)$ & $1,1,1,1,1,1$ \\
\hline $\mathrm{J}$ & 6 & 0 & 0 & - & $8.0(7-12)$ & $1,1,1,1,1,1$ \\
\hline
\end{tabular}

Filgrastim use duration and hospital duration from start of chemotherapy, days are shown average (min-max). Neutropenia (Grade 4) : an absolute neutrophil count $(\mathrm{ANC})<500 / \mu \mathrm{L}$.

cancer patients ${ }^{10)}$ or febrile neutropenia ${ }^{4-6)}$ more than filgrastim prophylaxis. We also had similar results to these reports instead of lower pegfilgrastim dose. Weycker et al. suggested that shorter courses of filgrastim prophylaxis are associated with increased risk of hospitalization. ${ }^{11)}$ In our study, the shortest duration of filgrastim was two days (Table 4), and in many cycles, duration of filgrastim was shorter than duration designed in clinical trial: $10-11 \mathrm{~d}^{7,12}$ The cause for high incident rate of FN in the FG group was considered to be short duration of filgrastim; however, daily G-CSF such as filgrastim has frequently been used in a short duration in clinical practice. ${ }^{4,11)}$ Pegfilgrastim is more favorable in this point.

Use of G-CSF for prophylaxis helps to reduce incidence of severe neutropenia and $\mathrm{FN}$ and enable higher dosage treatment in the DA-EPOCH-R regimen. Khaled et al. reported that the EPOCH regimen without dose adjustment had worse overall survival than the CHOP regimen for NHL patients. ${ }^{13)}$ Adjustments of chemotherapy dosage that depend on individual tolerability is also thought to affect clinical outcome. ${ }^{3)}$ There are few reports that show the correlation between dose level and overall survival (OS) in the DA-EPOCH-R regimen. In contrast, several reports showed no correlation between OS and dose level. ${ }^{3,14)}$ Lamar et al. reported that the number of completed cycles of DA-EPOCH-R was associated with NHL patients' death, disease progression, or relapse at 2 years in NHL patients. ${ }^{14)}$ Our study showed that pegfilgrastim is thought to be better than filgrastim for maintaining RDI.

Our study has shown that pegfilgrastim more significantly reduced hospitalization duration than filgrastim in total cycle analysis. Looking at the first cycle, pegfilgrastim also significantly reduced hospitalization duration compared with filgrastim (PEG group without patient $\mathrm{G} v s$. FG group, $12.0 \mathrm{~d} v s .19 .0 \mathrm{~d}$, $p<0.01$ ). In our hospital, filgrastim is administered daily during the hospital stay in the DA-EPOCH-R regimen. Conversely, pegfilgrastim is used only one time in each chemotherapy cycle. When we use pegfilgrastim, we can reduce hospitalization duration and contribute to improving the patient's quality of life. The reduction of hospital duration seemed to decrease medical cost. However, there has been no study about cost-benefit performance for using filgrastim versus pegfilgrastim for primary prophylaxis of FN in Japan. Thus, further study focused on the medical cost of FN treatment is required to discuss this important point.

Our study had several limitations; 1) we retrospectively evaluated NHL patients at a single medical center, so it seems our study population might not be representative of the general NHL patient population; 2) dose adjustment after the second cycle was decided by the physician, and in some cases the physician did not increase the dosage to upper limit.

\section{CONCLUSION}

Our retrospective study showed that pegfilgrastim may be better than daily filgrastim for dose adjustment and as the primary prophylaxis of $\mathrm{FN}$ in the 
DA-EPOCH-R regimen. A large-scale study is needed to validate our results.

Acknowledgements I would like to thank R. Kawano, Associate professor, Center for Integrated Medical Research, Hiroshima University Hospital, for statistical advice.

Conflict of Interest The authors declare no conflict of interest.

Supplementary Materials The online version of this article contains supplementary materials.

\section{REFERENCES}

1) "Clinical Practice Guideline for FN," ed. by Japanese Society of Medical Oncology, Nankodo Co., Ltd., Tokyo, 2012.

2) Pettengell R., Schwenkglenks M., Bosly A., Ann. Hematol., 87, 429-430 (2008).

3) Wilson W. H., Grossbard M. L., Pittaluga S., Cole D., Pearson D., Drbohlav N., Steinberg S. M., Little R. F., Janik J., Gutierrez M., Raffeld M., Staudt L., Cheson B. D., Longo D. L., Harris N., Jaffe E. S., Chabner B. A., Wittes R., Balis F., Blood, 99, 2685-2693 (2002).

4) Cooper K. L., Madan J., Whyte S., Stevenson M. D., Akehurst R. L., BMC Cancer, 11, 404 (2011).

5) von M. G., Kümmel S., du B. A., Eiermann W., Eidtmann H., Gerber B., Hilfrich. J., Huober J., Costa S. D., Jackisch C., Grasshoff S. T., Vescia S., Skacel T., Loibl S., Mehta K. M., Kaufmann M., Ann. Oncol., 19, 292 -298 (2008).
6) Pinto L., Liu Z., Doan Q., Bernal M., Dubois R., Lyman G., Curr. Med. Res. Opin., 23, 2283-2295 (2007).

7) Kubo K., Miyazaki Y., Murayama T., Shimazaki R., Usui N., Urabe A., Hotta T., Tamura K., Br. J. Haematol., 174, 563-570 (2016).

8) Huang J. J., Xia Y., Wang Y., Liu P. P., Bi X. W., Sun P., Lin T. Y., Jiang W. Q., Li Z. M., Oncotarget, 7, 41242-41250 (2016).

9) Wilson W. H., Dunleavy K., Pittaluga S., Hegde U., Grant N., Steinberg S. M., Raffeld M., Gutierrez M., Chabner B. A., Staudt L., Jaffe E. S., Janik J. E., J. Clin. Oncol., 26, 2717-2724 (2008)

10) Naeim A., Henk H. J., Becker L., Chia V., Badre S., Li X., Deeter R., BMC Cancer, 13, 11 (2013).

11) Weycker D., Hackett J., Edelsberg J. S., Oster G., Glass A. G., Ann. Pharmacother., 40, 402 -407 (2006).

12) Vose J. M., Crump M., Lazarus H., Emmanouilides C., Schenkein D., Moore J., Frankel S., Flinn I., Lovelace W., Hackett J., Liang B. C., J. Clin. Oncol., 21, 514-519 (2003).

13) Khaled H. M., Zekri Z. K., Mokhtar N., Ali N. M., Darwish T., Elattar I., Gaafar R., Moawad M. S., Ann. Oncol., 10, 1489-1492 (1999) .

14) Lamar Z. S., Fino N., Palmer J., Gruber L., Morris B. B., Raetskaya-Solntseva O., Kennedy L., Vaidya R., Hurd D., Zamkoff K., Clin. Lymphoma Myeloma Leuk., 16, 76-81 (2016) . 